\title{
Paper park performance: Mexico's natural protected areas in the 1990s
}

\author{
Allen Blackman ${ }^{\mathrm{a}, *}$, Alexander Pfaff ${ }^{\mathrm{b}, 1}$, Juan Robalino ${ }^{\mathrm{c}, 2}$ \\ ${ }^{a}$ Resources for the Future, 1616 P Street, Washington, DC 20036, United States \\ ${ }^{\mathrm{b}}$ Sanford School of Public Policy, Duke University, Durham, NC 27708, United States \\ ${ }^{\mathrm{c}}$ Environment for Development Center for Central America (EfD-CA), Centro Agronómico Tropical de Investigación y Enseñanza, CATIE 7170, Cartago, \\ Turrialba 30501, Costa Rica
}

\section{A R T I C L E I N F O}

\section{Article history:}

Received 18 February 2014

Received in revised form 15 October 2014

Accepted 5 December 2014

Available online 13 January 2015

\section{Keywords:}

Protected area

Deforestation

Mexico

Matching

\begin{abstract}
A B S T R A C T
Although developing countries have established scores of new protected areas over the past three decades, they often amount to little more than "paper parks" that are chronically short of the financial, human, and technical resources needed for effective management. It is not clear whether and how severely under-resourced parks affect deforestation. In principle, they could either stem it by, for example, creating an expectation of future enforcement, or they could spur it by, for example, creating open access regimes. We examine the effect of Mexico's natural protected areas (NPAs) on deforestation from 1993 to 2000, a period when forest clearing was rampant and the vast majority of protected areas had negligible resources or management. We use high-resolution satellite data to measure deforestation and (covariate and propensity score) matching to control for NPAs' nonrandom siting and for spillovers. Our broad finding is that Mexico's paper parks had heterogeneous effects both inside and outside their borders. More specifically, at the national-level, we cannot reject the null hypothesis that NPAs had zero average effect on clearing inside their borders, nor can we reject a similar hypothesis for spillover clearing outside their borders. However, we can detect statistically and economically significant insideand outside-NPA effects for certain geographic regions. Moreover, these effects have different signs depending on the region. Finally, we find that NPAs with certain characteristics were more effective at stemming deforestation inside their borders, namely, those that were large, new, mixed use, and relatively well-funded. Taken together, these results suggest that paper parks have the potential to either reduce or exacerbate tropical deforestation and highlight the need for further research on the conditions that lead to each outcome.
\end{abstract}

(c) 2014 Elsevier Ltd. All rights reserved.

\section{Introduction}

Tropical deforestation remains a pressing concern. For example, in both Latin America and Africa, deforestation rates averaged onehalf of one percent per year in the first decade of the 2000s, five times the global rate (FAO, 2011). This deforestation contributes to a host of global and local environmental problems including biodiversity loss, climate change, soil erosion, and flooding (Harris et al., 2012; Gibson et al., 2011; Chomitz, 2007). Protected areas, or parks, are a cornerstone of the policy response. Although the number of parks in tropical countries has expanded dramatically in the past three

\footnotetext{
* Corresponding and senior author. Tel.: +1 202328 5073; fax: +1 2029393460. E-mail addresses: blackman@rff.org (A. Blackman),

alex.pfaff@duke.edu (A.Pfaff), robalino@catie.ac.cr (J. Robalino).

1 Tel.: +1 9196139240 .

2 Tel.: +506 25582522 .
}

decades, in general, insufficient financial and human resources have been devoted to managing them (Balmford et al., 2003; Bruner et al., 2004; Wilkie et al., 2001; WDPA, 2014). The term paper parks has been used to characterize extreme cases of insufficient funding and management capacity (Bonham et al., 2008; Carey et al., 2000).

Given the proliferation of severely under-resourced parks in tropical countries, it is important for policymakers to understand whether and under what circumstances they help stem deforestation. Ex ante, the answer is not obvious. On one hand, paper parks could help stem forest clearing if loggers, ranchers, and other agents of forest-cover change are deterred by the threat of future regulatory enforcement, nonregulatory sanctions, or social mores. But on the other hand, establishing paper parks could contribute to deforestation by creating de facto open-access regimes where extractive activities can be pursued with impunity.

Rigorous evidence on this issue is thin. This is not to say that studies of park performance in developing countries are lacking. A considerable literature uses remotely sensed (satellite and airplane), 
survey, and other quantitative data to gauge the effect of a park or set of parks on forest-cover change (Geldmann et al., 2013; Nagendra, 2008; Naughton-Treves et al., 2005). However, many of these studies have methodological limitations that tend to bias their estimates of effectiveness upward (Blackman, 2013; Joppa and Pfaff, 2010). Many measure effectiveness by simply comparing rates of deforestation inside and outside parks, without controlling for the fact that parks are typically sited on land with preexisting characteristics-such as inaccessibility and rough terrain-that inhibit land-cover change (Joppa and Pfaff, 2009). As a result, these evaluations give parks credit for stemming deforestation that is actually due to the characteristics of the land on which they are sited. In addition, many studies do not control for leakage, the tendency of some parks to shift forest-cover change to nearby areas.

A newly emerging literature relies on matching and other statistical ("program evaluation") techniques to correct for these problems (Blackman, 2013; Joppa and Pfaff, 2010). Because this approach is relatively new, however, questions remain. To our knowledge, no such study has focused explicitly on the issue of paper parks. In addition, rigorous analysis of Mexican parks is scarce.

To help fill those gaps, we evaluate the effectiveness of all 56 protected areas established in Mexico prior to 1993 in stemming deforestation between 1993 and 2000. As discussed below, financial and human resources allocated to parks during this period were minimal. We use high-resolution land-cover data derived from satellite images along with statistical techniques (covariate and propensity score matching) that control for nonrandom siting. We address three questions about the 56 parks: What effect did they have on deforestation inside their borders? What effect did they have on deforestation outside their borders? Were parks with certain characteristics particularly effective in stemming deforestation?

\subsection{Background}

\subsubsection{Deforestation}

Mexico's forests, more than half of which are primary, comprise 65 million hectares, one-third of the national territory (FAO, 2011). The majority are governed by more than 2000 communal forest management units called ejidos and communidades, an artifact of the land reform that accompanied the Mexican revolution (FAO, 2011; Madrid et al., 2010; Bray et al., 2006). Historically, deforestation has been a severe problem in Mexico. Between 1990 and 2000, clearing of all types of forests averaged just over half of 1 percent per year, generating the seventh-highest net annual forest loss of any country in the world, and the clearing of primary forests averaged more than 1 percent per year (FAO, 2011).

\subsubsection{Natural protected areas}

Although Mexico established more than 30 NPAs between 1917 and 1979, most were quite small. The total land area in NPAs did not grow substantially until the 1980s (Fig. 1). By 1993, 56 NPAs comprising more than 6.5 million hectares had been created.

Throughout this period of rapid expansion, the creation and administration of NPAs were not coordinated at the national level. Mexico's 1988 comprehensive environmental law provided the legal underpinnings for the National System of Natural Protected Areas (Sistema Nacional de Áreas Protegidas, SINAP), administered by the Ministry of the Environment. The system was formally inaugurated four years later, in 1992. The same year, the Global Environmental Facility (GEF) provided US\$25 million to support an elite group of 10 NPAs within SINAP (World Bank, 2002; Pérez Gil Salcido, 1995).

Despite those positive developments, during the 1990s-the period during which we measure NPAs' effect on deforestationvirtually all Mexican NPAs were paper parks. SINAP was a system in name only: central management and coordination were minimal (Pérez Gil Salcido, 1995). Moreover, funding, staffing, planning, and enforcement for all but the elite group of 10 NPAs receiving GEF funds were grossly insufficient. In fact, the vast majority of parks lacked any financial support, personnel, or management planning (Rivera and Muñoz, 2006; Cervigni and Brizzi, 2001; Pérez Gil Salcido, 1995). From 1990 to 1994, Mexican funding for all nonelite NPAs was carved out of budgets for other programs and averaged just $\$ 60,000$ per year, roughly US $\$ 0.01$ per hectare per year (Rivera and Muñoz, 2006) (Fig. 3). In 1995, for the first time, the national budget included a specific allocation for SINAP. Over the next four years, that allocation increased somewhat but still averaged less than US\$0.85 per hectare per year, far less than what was needed for the most basic management (Rivera and Muñoz, 2006; Cervigni and Brizzi, 2001). By comparison, the United States, Canada, and European countries currently spend an average of US $\$ 28.00$ per hectare per year on protected areas, and Mesoamerican countries spend an average of US\$4.59 (Flores, 2010; Bovarnick et al., 2010).

It was not until the 2000s that SINAP funding and administration improved significantly. In 2000, administration of SINAP was

$\square$ Area added $\quad$ Cumulative area

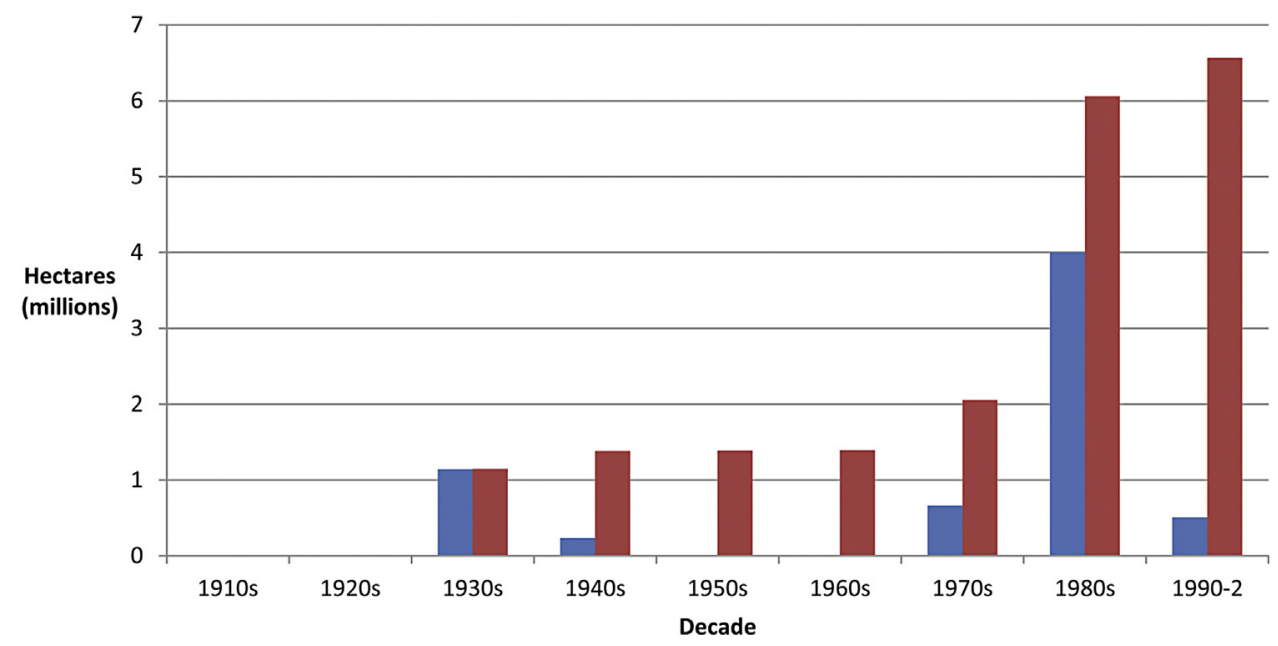

Fig. 1. Land in Mexico's natural protected areas, by decade. 
transferred to a new, semi-autonomous institution called the National Commission for NPAs (Comisión Nacional de Áreas Naturales Protegidas, CONANP), consisting of a headquarters in Mexico City and nine regional offices (Fig. 2). SINAP's budget and activities have increased markedly since that time (Rivera and Muñoz, 2006).

Finally, it is important to note that in addition to chronic shortages of resources, Mexican NPAs face a second significant challenge: less than one tenth of NPA land is state owned. The majority is owned by ejidos, communidades, and other communal tenure institutions and at least 10 percent is owned by private concerns (World Bank, 2002). Therefore, NPA effectiveness in stemming deforestation depends critically on creating incentives for communal forest management units to adopt sustainable practices (Cervigni and Brizzi, 2001; Pérez Gil Salcido, 1995). However, most of these units, particularly the smaller ones, lack the capacity to do that (Anta Fonseca, 2006). Indeed, previous research indicates that some communal tenure was associated with higher rates of deforestation during the 1990s (BonillaMoheno et al., 2013). Given the role of land tenure in NPA management, it will be important to control for this characteristic in our statistical analysis.

\subsubsection{Previous evaluations}

What evidence do we have on the effectiveness of Mexican NPAs in stemming deforestation during the 1990s? As noted above, evaluations of protected areas using matching and other program evaluation techniques to control for both nonrandom siting and leakage have only recently begun to appear. Studies using other methods have reached varying conclusions. For example, Mas (2005) evaluates the effect on deforestation of a single large NPA in southeastern Mexico (the Calakmul Biosphere Reserve) by comparing 1993-2000 rates of forest clearing inside the NPA and rates in similar adjacent areas. He concludes that NPAs halved the annual deforestation rate. Using similar methods, Foo and Sánchez-Cordero (2008) examine the 69 NPAs established prior to 1997 and find that the majority were "effective" in stemming deforestation from 1993-2002. By contrast, Durán-Medina et al. (2005) find that the average 1980-2000 rate of deforestation in a national sample of more than 50 NPAs was significantly higher than that for selected community forestry enterprises in two states in southern Mexico (Guerrero and Qintana Roo).

More recent rigorous evaluations of Mexican NPAs during the first decade of the 2000s-which as noted above, was a period of substantially increased funding and management-suggest that they have been effective in stemming deforestation inside their borders. Pfaff et al. (2014a) find that on average, NPAs avoided about 3 percent deforestation inside their borders between 2000 and 2005 while Sims and Alix-Garcia (2014) find that (a different sample of) NPAs reduced national baseline deforestation by 20 percent between 2000 and 2010 .

\section{Methods}

\subsection{NPAs' effect on deforestation inside their borders}

\subsubsection{Matching estimators}

As noted above, the main challenge we face in attempting to accurately measure pre-1993 NPAs' effect on deforestation is that they were not randomly sited. Rather, as we will show, these NPAs were disproportionately located on land with certain preexisting geophysical, climatological, and socioeconomic characteristics that affect deforestation. For example, they tended to be sited relatively far from population centers and at relatively high

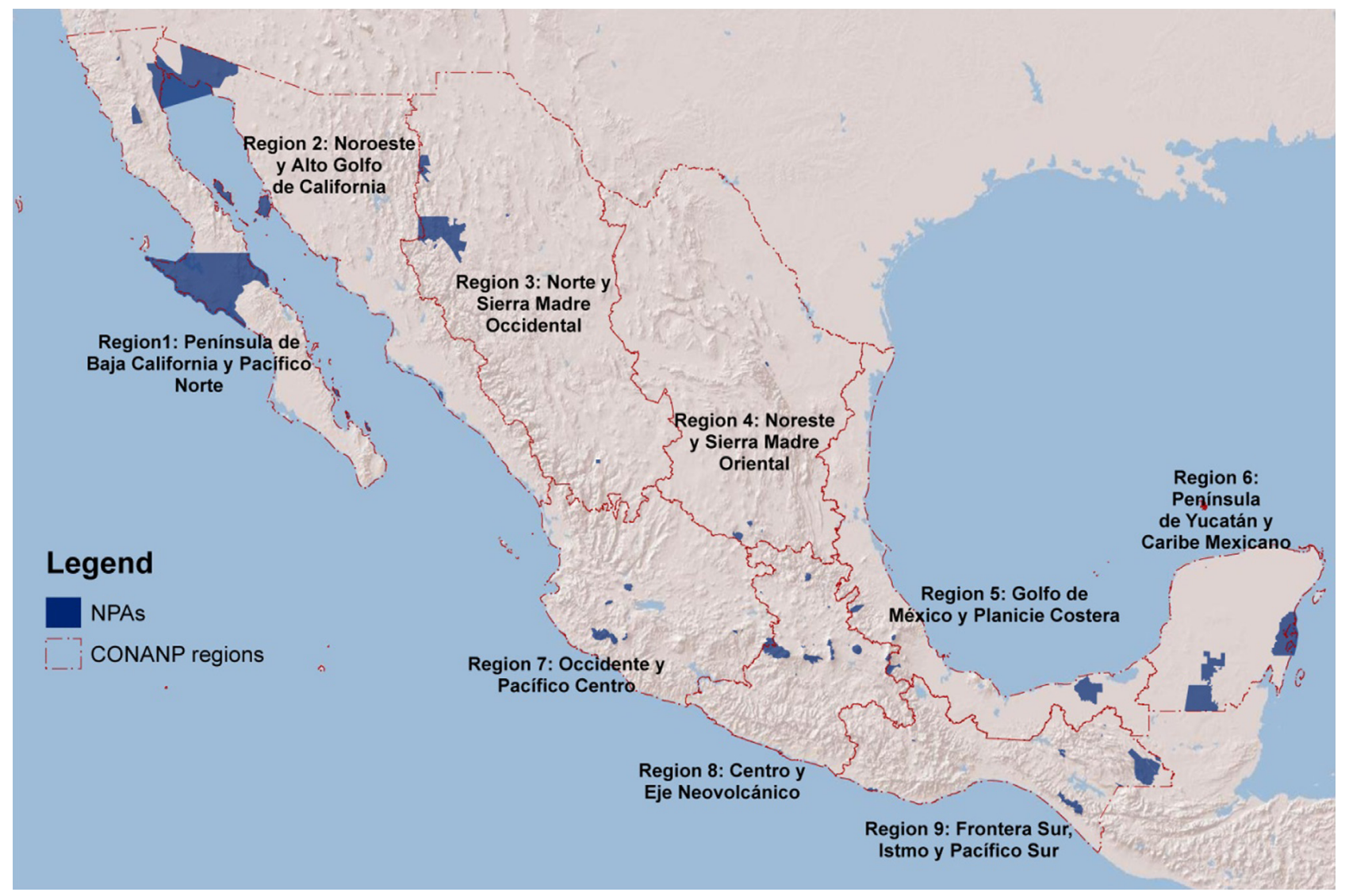

Fig. 2. Natural protected areas created prior to 1993 and CONANP regions. 


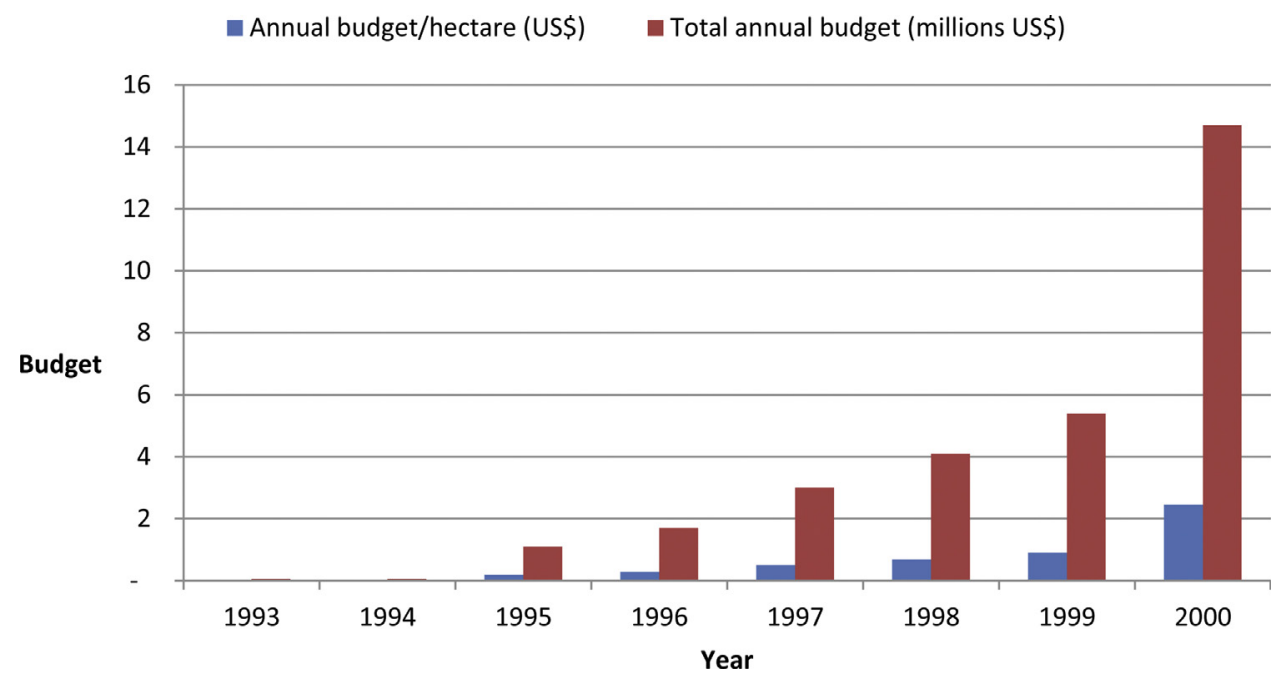

Fig. 3. Annual budget for natural protected areas, 1993-2000.

elevations, both attributes that tend to discourage deforestation. Therefore, measuring NPAs' effect on deforestation by simply comparing the average deforestation rate for plots inside NPAs and a random sample outside-with the latter average serving as the counterfactual (what would have happened absent the NPA)would conflate NPAs' effects on deforestation with those of preexisting land characteristics. In general, the resulting estimates of NPA effectiveness would be biased upwards.

To control for such selection bias, we use matching techniques. That is, following Andam et al. (2008) and Nelson and Chomitz (2011), among others, we construct a sample of matched control plots outside NPAs that are very similar to the plots inside in terms of observable characteristics that affect deforestation. We measure NPAs' effect-the average treatment effect on the treated (ATT)-by comparing the average rates of deforestation on plots inside the NPAs and on the matched sample of plots outside.

The key identifying assumption for matching estimators, typically referred to as "ignorability" or "conditional independence," is that conditional only on observed characteristics, nonrandom selection into the treatment is ignorable for purposes of measuring treatment effects (Stuart, 2010; Caliendo and Kopeinig, 2008). In terms of our application, the assumption is that we are able to observe and control for all important confounding factors, that is, variables that affect both the probabilities that plots were included in pre-1993 NPAs and that they were cleared between 1993 and 2000. This assumption is untestable. In practice, we recognize that it may not hold. For example, stumpage values, which we do not observe, may be negatively correlated with protection (if policy makers tend to shy away from protecting forests where logging earns particularly high profits) and positively correlated with deforestation (if loggers tend to target such forests). In principle, an inability to control for stumpage values could bias our treatment effects estimates upwards. As discussed in Section 2.1.3, to control for unobserved spatial heterogeneity, in addition to estimating treatment effects for a national sample, we estimate them for seven regional subsamples within which we would expect less unobserved heterogeneity. In addition, as discussed in Section 4.3, we use Rosenbaum bounds (Rosenbaum, 2002) to check for the sensitivity of our results to this type of heterogeneity.

A variety of techniques can be used to match treated (NPA) and control (non-NPA) observations and to compare outcomes for each subsample (Stuart, 2010; Caliendo and Kopeinig, 2008). To ensure robustness, we use four estimators. For each of these estimators, matching is with replacement, we enforce a common support, and we cluster standard errors at the municipio (county)-level to control for spatial correlation of errors.

Nearest neighbor one-to-one covariate matching. The first estimator uses Mahalanobis distance, a scale-invariant measure of distance in n-dimensional space, to measure similarity among plots. Each NPA plot is matched to the one "nearest" non-NPA plot.

Probit with matched controls. The second estimator combines nearest neighbor one-to-one covariate matching with regression, a hybrid approach that typically generates treatment effects estimates that are more accurate and more robust to misspecification than does either matching or regression alone (Imbens and Wooldridge, 2009; Ho et al., 2007). We estimate a plot-level probit regression in which the sample is limited to plots inside NPAs and matched plots outside, the dependent variable is a dummy variable that indicates whether a plot was cleared between 1993 and 2000, the key independent variable is a dummy indicating whether the plot was in an NPA, and control variables are socioeconomic, geophysical, and climatological plot characteristics. Because matching is with replacement, we weight non-NPA observations that constitute the control group based on the number of times they were included as matches (Abadie and Imbens, 2006). ATT is given by the marginal effect of the treatment dummy variable.

Nearest neighbor one-to-one propensity score matching. The third estimator uses propensity scores-the probability that a plot is inside an NPA as predicted by a probit regression-as a measure of similarity between NPA and non-NPA plots. A propensity score can be interpreted as a weighted index of plot characteristics, where the weights reflect the importance of each characteristic in explaining whether observations were included in the treatment group (Rosenbaum and Rubin, 1983). Again, each NPA plot is matched to the one nearest non-NPA plot.

Nearest neighbor one-to-eight propensity score matching with caliper. The fourth estimator uses propensity scores to match each NPA plot to the eight nearest non-NPA plots, with the average outcome for these eight plots serving as the counterfactual. To guard against low-quality matches, we use a onehalf standard deviation caliper; that is, we drop from the matching sample all treated observations for which the "distance" to the nearest non-NPA plot is more than one-half 
standard deviation of the distribution of propensity scores for the entire sample.

The reliability of matching estimators depends critically on their ability to identify control units (non-NPA plots) that are very similar to treated units (NPA plots) (Stuart, 2010; Caliendo and Kopeinig, 2008). Following Rosenbaum and Rubin (1983), we assess matching quality using median standardized bias (MSB)the median across our six control variables of the (varianceadjusted) percentage difference between the mean for the NPA sample and the matched non-NPA sample. A univariate summary statistic, MSB provides a concise means of assessing matching quality for multiple estimators and samples. Although a clear threshold for acceptable MSB does not exist, a statistic below 3-5 percent is generally viewed as sufficient (Caliendo and Kopeinig, 2008).

Among our four estimators, in interpreting our results, we place more weight on the two using covariate matching. The reason is that as discussed below, they generate higher quality matches as measured by MSB. Hence, our propensity score matching results are best seen as robustness checks on our covariate matching results.

\subsubsection{Naïve estimators}

In addition to the four matching estimators discussed above, we also use two naïve estimators that do not control for selection bias and therefore are unlikely to generate unbiased ATT estimates. The purpose is to shed light on the value of our matching approach. The first naïve estimator is the simple difference between the average rates of deforestation on all NPA plots in our sample and all nonNPA plots (e.g., CONANP, 2003). The second is the difference between the average rates of deforestation on all NPA plots in our sample and all non-NPA plots located within a distance band surrounding NPAs (e.g., Mas, 2005; Foo and Sánchez-Cordero, 2008). We use a $20 \mathrm{~km}$ distance band.

As noted above, the first estimator can generate biased results because it does not control for the nonrandom siting of parks. The second relies on a simple form of matching to control for selection bias. Its validity rests on the assumption that plots close to NPAs are similar to those inside. There are two problems with this approach. First, it may not be true that nearby plots are similar. Second, legal protections inside NPAs may result in spillover effects, which raise or lower deforestation rates just outside NPAs, thereby biasing this estimator upward or downward.

\subsubsection{Regional subsamples}

Using the above methods, we estimate ATT for a national sample and for subsamples corresponding to CONANP's nine regions (Fig. 2). Because of the small number and size of NPAs in Regions 1,2,4, and 5 , we combine Region 1 with Region 2, and Region 4 with Region 5. Estimating ATT using regional subsamples serves two related purposes. First, it mitigates aggregation bias. Some NPAs may have minimal effects on deforestation (or may actually spur deforestation) while others have large effects. In a large national sample, such countervailing effects may negate each other. Second, as noted above, regional models help control for unobserved heterogeneity.

\subsection{NPAs' effect on deforestation outside their borders}

NPAs can have spillover effects on deforestation in adjacent areas that are either positive or negative. Positive spillovers refer to effects that have the same sign inside and outside NPAs (e.g., reducing deforestation both outside and inside) while negative spillovers refer to effects that have the opposite sign (e.g., reducing deforestation inside and increasing it outside). Measuring NPAs' spillover effects confronts the same challenge as identifying NPAs' effect on deforestation within their borders: NPAs tend to be sited in areas with preexisting characteristics that affect deforestation. To control for this selection effect, we again rely on matching estimators. We compare the rate of deforestation on a sample of plots adjacent to NPAs with the rate of deforestation on a matched sample of plots that are not adjacent to (or inside) NPAs (e.g., Pfaff et al., 2014b; Robalino et al., 2012a,b; Andam et al., 2008). We use the same four matching estimators discussed in Section 2.1.1. We define 'adjacent' as location within $20 \mathrm{~km}$ of an NPA border.

\subsection{Characteristics of effective NPAs}

We use interaction terms along with a combination of regression and matching to test whether NPAs with certain observable characteristics were more effective than average in stemming deforestation inside their borders (e.g., Alix-Garcia et al., 2012). We first use nearest neighbor 1-1 Mahalanobis matching to identify control plots similar to treated plots in a national sample. Next, using the subsample of treated and matched control plots, we regress clearing onto a set of control variables and interactions between a binary treatment dummy variable and an NPA characteristic. In other words, we use the second covariate matching estimator discussed above along with interaction terms. We examine four NPA characteristics (which we discuss in more detail in Section 3.2): size, vintage, management regime, and funding. For this analysis of NPA characteristics, we use a national sample that omits Region 3 because, as discussed below, the small number of NPAs in this region are outliers in the sense of having unusually high average deforestation rates. If included in the analysis, they drive our results.

\section{Data}

\subsection{Sample}

We use a dimensionless plot of land defined by latitude and longitude coordinates as our unit of analysis. Drawing on the spatial data sources listed in Table 1, for each plot, we collected spatially explicit data on outcomes (deforestation), treatment (location in or near an NPA), and control variables-a variety of socioeconomic, geophysical, and climatological land characteristics. In addition, for plots inside NPAs, we collected data on NPA characteristics, which we used to construct interaction terms. The land characteristics data were originally compiled by the National Ecology and Climate Change Institute (Instituto Nacional de Ecologia $y$ Cambio Climáctico, INECC), the research branch of Mexico's Ministry of Environment and Natural Resources.

From among the billions of plots that make up the national territory of Mexico, we selected a computationally feasible sample to be used in the matching analysis as follows. First, we overlaid a 2$\mathrm{km}$ rectangular grid (i.e., a pattern with gridlines $2 \mathrm{~km}$ apart) onto a map of Mexico and selected the plots where the gridlines crossed. This procedure generated just over 500,000 plots. Next, we dropped roughly 330,000 plots that were not forested in 1993 , since our aim is to explain the effect of NPAs on deforestation between 1993 and 2000 . We also dropped approximately 5600 plots in NPAs that were established after 1992 to ensure that our sample comprises only plots that were treated (i.e., in an NPA) either for our entire 19932000 study period or for none of it. Finally, we dropped roughly 3000 plots for which data on land tenure were missing. The final sample comprises 137,632 plots, 5574 of which are inside pre-1993 NPAs and 132,058 of which are outside all NPAs.

\subsection{Variables}

Table 1 lists the variables in our plot-level database along with the sources of data used to construct them. Our outcome variable is 
Table 1

Variables, means for two subsamples (unprotected, protected), and difference-in-means test.

\begin{tabular}{|c|c|c|c|c|c|c|}
\hline Variable & Source & Units & $\begin{array}{l}\text { Scaling } \\
\text { factor }\end{array}$ & $\begin{array}{l}\text { Mean NPA =1 } \\
(n=5574)\end{array}$ & $\begin{array}{l}\text { Mean NPA }=0 \\
(n=132,058)\end{array}$ & $t$-Test \\
\hline \multicolumn{7}{|l|}{ Outcome } \\
\hline Cleared during 1993-2000? & $\begin{array}{l}\text { Velázquez et al. } \\
\text { (2002) }\end{array}$ & $(0 / 1)$ & 100 & 11.61 & 15.79 & *** \\
\hline \multicolumn{7}{|l|}{ Treatment } \\
\hline Located pre-1993 NPA? & CONANP (2007) & $(0 / 1)$ & 100 & 100.00 & 0.00 & $* * *$ \\
\hline \multicolumn{7}{|l|}{ Controls } \\
\hline Communal land tenure 1984-1989 & RAN (undated) & $(0 / 1)$ & 100 & 53.32 & 64.15 & $* * *$ \\
\hline More than $75 \%$ pop. locality indigenous? & CONABIO (1999) & $(0 / 1)$ & 100 & 10.19 & 16.95 & *** \\
\hline Travel time to nearest city w/pop. $>15 \mathrm{~K}$ & INECC (undated) & $\min$ & 0.1 & 40.30 & 25.58 & $* * *$ \\
\hline Elevation & INEGI (undated) & $\mathrm{m}$ & 0.01 & 12.20 & 11.30 & $* * *$ \\
\hline Slope $(100 \tan (\pi$ angle $/ 180))$ & INEGI (undated) & $\%$ & 1 & 12.57 & 18.15 & $* * *$ \\
\hline Median annual precipitation & CONABIO (1998) & $\mathrm{mm}$ & 0.01 & 12.71 & 11.40 & $* * *$ \\
\hline \multicolumn{7}{|l|}{ Interactions $\mathrm{a}^{\mathrm{a}}$} \\
\hline NPA surface area & CONANP (2007) & ha & 0.0001 & 38.77 & $\mathrm{n} / \mathrm{a}$ & $\mathrm{n} / \mathrm{a}$ \\
\hline NPA vintage & CONANP (2007) & $(0 / 1)$ & 100 & 32.67 & $\mathrm{n} / \mathrm{a}$ & $\mathrm{n} / \mathrm{a}$ \\
\hline NPA allows some extractive activities? & WDPA (2014) & $(0 / 1)$ & 100 & 12.91 & $\mathrm{n} / \mathrm{a}$ & $\mathrm{n} / \mathrm{a}$ \\
\hline NPA received GEF funding? & World Bank (2002) & $(0 / 1)$ & 100 & 77.53 & $\mathrm{n} / \mathrm{a}$ & $\mathrm{n} / \mathrm{a}$ \\
\hline
\end{tabular}

NPA, natural protected area.

$* p<10 \%$.

*** $p<5 \%$.

$p<1 \%$.

n/a, not applicable.

a Variables used only to create interaction terms (see Section 2.3).

a dummy variable that identifies plots that were cleared-i.e., converted from tree cover to no tree cover-at some point between 1993 and 2000. It was constructed from compatible 1:250,000 scale digital land-cover maps for 1993 and 2000, which, in turn, were derived from $30 \mathrm{~m}^{2}$ resolution LANDSAT satellite images (Velázquez et al., 2002).

Our treatment variable is a dummy that identifies plots located in pre-1993 NPAs. Table A1 in the Appendix lists the 56 NPAs included in our analysis.

The control variables include six socioeconomic, geophysical, and climatological land characteristics that drive deforestation (Boucher et al., 2011; Chomitz, 2007; Kaimowitz and Angelsen, 1998). The first is a dummy that identifies plots under ejido, communidad, or other types of communal tenure. The second is a dummy that identifies plots in heavily indigenous townships, specifically those where more than three-quarters of the population speak an indigenous language. The third, fourth and fifth are rainfall, elevation and slope. The last control variable is travel time to the nearest city with a population larger than 15,000 .

We limit the number of control variables because covariate matching becomes computationally unmanageable with a large set of covariates (Stuart, 2010). Qualitative results from matching models with larger sets covariates, including for soil types, other types of tenure, and travel time to small population centers, generate results that are quite similar to those presented below.

Finally, we use four NPA-level variables to generate the interaction terms used in the analysis of the characteristics of effective NPAs. The first is the surface area of the NPA in hectares. The second is the age of the NPA in years. The third is a dummy that indicates whether the NPA was mixed use (allowed "sustainable" extractive activities) as opposed to strictly protected (prohibited all extractive activity). We use International Union for the Conservation of Nature (IUCN) classifications to distinguish between the two groups: IUCN categories V and VI comprise the mixed-use group (e.g., Ferraro et al., 2013; Nelson and Chomitz, 2011). The final NPA-level variable indicates whether, as discussed in Section 1, the protected area was among the 10 that received GEF funding during our study period.

\subsection{Summary statistics}

Table 1 presents variable means for two subsamples of plots, those inside pre-1993 NPAs and those outside, along with difference-in-means tests. These statistics indicate that both average deforestation rates and land characteristics are quite different inside and outside NPAs. As for deforestation, the average eight-year (1993-2000) rate of clearing on NPA plots was 12 percent and that on non-NPA plots was 16 percent. Ignoring nonrandom siting, these simple summary statistics suggest that on average, NPAs cut deforestation by 4 percent.

But the summary statistics in Table 1 also suggest that ignoring nonrandom siting is likely to bias evaluations of NPA effectiveness because plots inside and outside NPAs have very different preexisting characteristics that drive deforestation. Compared with plots in unprotected areas, those in NPAs tend not to be communally held or in townships dominated by indigenous peoples, and tend to be farther from large cities, higher, flatter, and wetter. Hence, these summary statistics point to the importance of controlling for preexisting plot characteristics in estimating ATT.

\section{Results}

For most of the dozens of combinations of estimators and subsamples discussed below, MSB (our measure of matching quality, presented in square brackets in our tables of results) is below the 3-5 percent threshold for acceptability (Tables 2 and 3). This is particularly true for the covariate matching estimators that we emphasize: in general they do a better job than our propensity score estimators of matching NPA plots to similar non-NPA plots. For the sake of concise exposition, in what follows, we restrict our discussion of matching balance to those cases in which MSB does not meet the 3-5 percent limit.

For both our naïve and matching estimators, we express ATTs as percent changes. Percent change is calculated as $\left(\left(R_{\mathrm{T}}-R_{\mathrm{C}}\right) /\right.$ $\left.R_{\mathrm{C}}\right) \times 100$ where $R_{\mathrm{T}}$ is the average deforestation rate for treated plots and $R_{\mathrm{C}}$ is the average deforestation rate for counterfactual (matched control) plots. 
Table 2

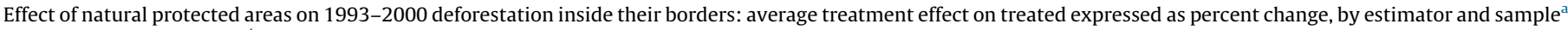
[median standardized bias $\left.{ }^{\mathrm{b}}\right]\left\{\Gamma^{* \mathrm{c}}\right\}$.

\begin{tabular}{|c|c|c|c|c|c|c|c|c|c|}
\hline \multirow[t]{3}{*}{ Estimator } & \multirow{3}{*}{ National } & \multicolumn{8}{|l|}{ Sample } \\
\hline & & \multicolumn{8}{|l|}{ Region(s) } \\
\hline & & $1 \& 2$ & 3 & $4 \& 5$ & 6 & 7 & 8 & 9 & All but 3 \\
\hline \multicolumn{10}{|l|}{ Naïve } \\
\hline Unmatched controls & $\begin{array}{l}-26.47^{* * * *} \\
{[21.77]}\end{array}$ & $\begin{array}{l}-36.25 \\
{[72.74]}\end{array}$ & $\begin{array}{l}132.78^{* * * *} \\
{[16.60]}\end{array}$ & $\begin{array}{l}-58.36^{* * * *} \\
{[35.95]}\end{array}$ & $\begin{array}{l}-87.91^{* * *} \\
{[30.66]}\end{array}$ & $\begin{array}{l}-11.60 \\
{[40.06]}\end{array}$ & $\begin{array}{l}-19.96^{*} \\
{[27.31]}\end{array}$ & $\begin{array}{l}-44.62^{* * *} \\
{[61.41]}\end{array}$ & $\begin{array}{l}-62.24^{* * *} \\
{[29.41]}\end{array}$ \\
\hline Distance band $0-20 \mathrm{~km}$ & $\begin{array}{l}-31.46^{* * *} \\
{[14.45]}\end{array}$ & $\begin{array}{l}-38.24^{*} \\
{[45.59]}\end{array}$ & $\begin{array}{l}93.22^{* * *} \\
{[28.86]}\end{array}$ & $\begin{array}{l}-61.36^{* * *} \\
{[32.83]}\end{array}$ & $\begin{array}{l}-80.83^{* * *} \\
{[49.83]}\end{array}$ & $\begin{array}{l}-16.53 \\
{[44.32]}\end{array}$ & $\begin{array}{l}-20.86^{*} \\
{[24.89]}\end{array}$ & $\begin{array}{l}-61.75^{* * *} \\
{[41.98]}\end{array}$ & $\begin{array}{l}-62.97^{* * *} \\
{[22.47]}\end{array}$ \\
\hline \multicolumn{10}{|l|}{ Covariate matching } \\
\hline Nearest neighbor $1-1$ & $\begin{array}{l}8.20 \\
{[0.56]} \\
\text { n/a }\end{array}$ & $\begin{array}{l}-62.09 \\
{[7.12]} \\
\text { n/a }\end{array}$ & $\begin{array}{l}156.06^{*} \\
{[1.13]} \\
\{2.60\}\end{array}$ & $\begin{array}{l}-28.54 \\
{[1.10]} \\
\text { n/a }\end{array}$ & $\begin{array}{l}-64.07^{* *} \\
{[2.03]} \\
\{3.80\}\end{array}$ & $\begin{array}{l}6.58 \\
{[2.07]} \\
\text { n/a }\end{array}$ & $\begin{array}{l}2.20 \\
{[0.61]} \\
\text { n/a }\end{array}$ & $\begin{array}{l}-41.17 \\
{[0.99]} \\
\text { n/a }\end{array}$ & $\begin{array}{l}-43.70^{* * *} \\
{[0.93]} \\
\{2.00\}\end{array}$ \\
\hline Probit $\mathrm{w} /$ matched controls & $\begin{array}{l}4.41 \\
{[0.56]}\end{array}$ & $\begin{array}{l}-58.03^{*} \\
{[7.12]}\end{array}$ & $\begin{array}{l}131.08^{* * *} \\
{[1.13]}\end{array}$ & $\begin{array}{l}-31.84 \\
{[1.10]}\end{array}$ & $\begin{array}{l}-55.89^{* * *} \\
{[2.03]}\end{array}$ & $\begin{array}{l}5.57 \\
{[2.07]}\end{array}$ & $\begin{array}{l}8.11 \\
{[0.61]}\end{array}$ & $\begin{array}{l}-33.77 \\
{[0.99]}\end{array}$ & $\begin{array}{l}-42.86^{* * *} \\
{[0.93]}\end{array}$ \\
\hline \multicolumn{10}{|l|}{ Propensity score matching } \\
\hline Nearest neighbor 1-1 & $\begin{array}{l}-2.35 \\
{[5.39]}\end{array}$ & $\begin{array}{l}-38.50 \\
{[34.02]}\end{array}$ & $\begin{array}{l}121.98 \\
{[2.34]}\end{array}$ & $\begin{array}{l}-50.53^{*} \\
{[9.86]}\end{array}$ & $\begin{array}{l}-67.83^{* * *} \\
{[9.42]}\end{array}$ & $\begin{array}{l}6.58 \\
{[3.80]}\end{array}$ & $\begin{array}{l}-9.72 \\
{[4.89]}\end{array}$ & $\begin{array}{l}-35.14 \\
{[3.01]}\end{array}$ & $\begin{array}{l}-50.65^{* * * *} \\
{[4.66]}\end{array}$ \\
\hline $\begin{array}{l}\text { Nearest neighbor } 1-8 \\
\text { caliper }\end{array}$ & $\begin{array}{l}-9.79 \\
{[3.85]}\end{array}$ & $\begin{array}{l}-59.88^{* *} \\
{[26.37]}\end{array}$ & $\begin{array}{l}123.54 \\
{[1.43]}\end{array}$ & $\begin{array}{l}-54.02^{* *} \\
{[3.94]}\end{array}$ & $\begin{array}{l}-72.30^{* * * *} \\
{[12.72]}\end{array}$ & $\begin{array}{l}11.15 \\
{[2.51]}\end{array}$ & $\begin{array}{l}-8.99 \\
{[7.80]}\end{array}$ & $\begin{array}{l}-49.26^{*} \\
{[5.28]}\end{array}$ & $\begin{array}{l}-51.39^{* * *} \\
{[4.52]}\end{array}$ \\
\hline $\begin{array}{l}\text { Outcome unmatched } \\
\text { control plots }\end{array}$ & 15.78 & 9.29 & 10.89 & 24.84 & 22.91 & 17.59 & 16.82 & 12.92 & 17.16 \\
\hline Outcome treatment plots & 11.61 & 5.91 & 25.35 & 10.34 & 2.77 & 15.55 & 13.47 & 7.16 & 6.48 \\
\hline No. plots & 137,632 & 14,940 & 30,444 & 12,252 & 21,606 & 20,441 & 15,103 & 22,846 & 107,188 \\
\hline No. plots treatment & 5574 & 186 & 1515 & 145 & 1983 & 418 & 349 & 978 & 4059 \\
\hline
\end{tabular}

${ }^{*} p<10 \%$.

** $p<5 \%$.

$p<1 \%$.

n/a, not applicable.

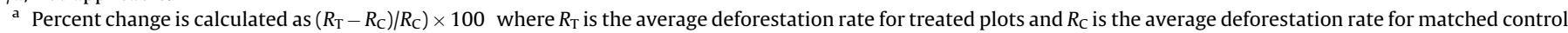

(counterfactual) plots. Standard errors for covariate and propensity score matching estimators are clustered at the municipio-level.

${ }^{b}$ For a given covariate, the standardized bias (SB) is the absolute value of the difference of means in the treated and matched untreated subsamples as a percentage of the square root of the average sample variance in both groups. We report the median SB for all covariates.

c Critical value of Rosenbaum's $\Gamma$.

Table 3

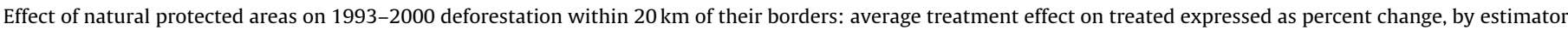
and sample ${ }^{\mathrm{a}}$ [median standardized bias $\left.{ }^{\mathrm{b}}\right]\left\{\Gamma^{* \mathrm{c}}\right\}$.

\begin{tabular}{|c|c|c|c|c|c|c|c|c|c|}
\hline \multirow[t]{3}{*}{ Estimator } & \multirow{3}{*}{ National } & \multicolumn{8}{|l|}{ Sample } \\
\hline & & \multicolumn{8}{|c|}{ Region(s) } \\
\hline & & $1 \& 2$ & 3 & $4 \& 5$ & 6 & 7 & 8 & 9 & All but 3 \\
\hline \multicolumn{10}{|l|}{ Covariate matching } \\
\hline \multirow[t]{3}{*}{ Nearest neighbor $1-1$} & 6.47 & 19.20 & 17.16 & 4.52 & $-29.10^{* * * *}$ & 6.21 & -7.58 & $35.58^{* *}$ & 6.64 \\
\hline & {$[0.07]$} & [1.12] & {$[0.57]$} & {$[0.16]$} & {$[1.73]$} & {$[0.30]$} & {$[0.76]$} & {$[0.10]$} & {$[0.28]$} \\
\hline & $\mathrm{n} / \mathrm{a}$ & $\mathrm{n} / \mathrm{a}$ & $\mathrm{n} / \mathrm{a}$ & $\mathrm{n} / \mathrm{a}$ & $\{1.60\}$ & $\mathrm{n} / \mathrm{a}$ & $\mathrm{n} / \mathrm{a}$ & $\{1.60\}$ & $\mathrm{n} / \mathrm{a}$ \\
\hline \multirow[t]{2}{*}{ Probit w/matched controls } & 34.55 & 17.59 & 16.02 & 4.24 & $-29.00^{* * *}$ & 6.51 & -6.73 & $33.64^{* * *}$ & 35.55 \\
\hline & {$[0.07]$} & [1.12] & {$[0.57]$} & {$[0.16]$} & [1.73] & {$[0.30]$} & {$[0.76]$} & {$[0.10]$} & {$[0.28]$} \\
\hline \multicolumn{10}{|l|}{ Propensity score matching } \\
\hline \multirow[t]{2}{*}{ Nearest neighbor $1-1$} & 5.74 & -1.54 & 24.74 & 28.26 & -13.77 & 6.09 & -3.91 & $46.17^{* * *}$ & 6.77 \\
\hline & {$[1.11]$} & [1.11] & [3.33] & [1.95] & [7.33] & [2.78] & [1.59] & [1.25] & {$[0.55]$} \\
\hline \multirow[t]{2}{*}{ Nearest neighbor $1-8$ caliper } & 5.68 & 5.99 & 15.71 & 22.69 & $-23.40^{*}$ & 9.77 & 0.47 & $41.21^{* * * *}$ & 5.87 \\
\hline & {$[1.35]$} & {$[1.72]$} & {$[2.24]$} & {$[1.45]$} & {$[6.90]$} & [2.26] & {$[0.96]$} & [1.87] & {$[0.90]$} \\
\hline $\begin{array}{l}\text { Median standardized bias } \\
\text { before match }\end{array}$ & 9.33 & 28.26 & 30.68 & 6.01 & 11.89 & 13.20 & 32.02 & 23.29 & 6.09 \\
\hline $\begin{array}{l}\text { Outcome unmatched } \\
\text { control plots }\end{array}$ & 15.43 & 9.22 & 10.53 & 24.29 & 26.53 & 16.98 & 16.77 & 10.96 & 17.05 \\
\hline Outcome treatment plots & 16.94 & 9.56 & 13.11 & 26.82 & 14.47 & 18.65 & 17.18 & 18.71 & 17.50 \\
\hline No. plots & 132,058 & 14,754 & 28,929 & 12,107 & 19,623 & 20,023 & 14,754 & 21,868 & 103,129 \\
\hline No. plots treatment & 31,090 & 2591 & 3957 & 2679 & 5874 & 7420 & 3039 & 5530 & 27,133 \\
\hline
\end{tabular}

$p<10 \%$.

${ }^{* *} p<5 \%$.

$p<1 \%$.

n/a, not applicable.

a Percent change is calculated as $\left.\left(R_{\mathrm{T}}-R_{\mathrm{C}}\right) / R_{\mathrm{C}}\right) \times 100$ where $R_{\mathrm{T}}$ is the average deforestation rate for treated plots and $R_{\mathrm{C}}$ is the average deforestation rate for matched control

(counterfactual) plots. Standard errors for covariate and propensity score matching estimators are clustered at the municipio-level.

${ }^{b}$ For a given covariate, the standardized bias (SB) is the absolute value of the difference of means in the treated and matched untreated subsamples as a percentage of the square root of the average sample variance in both groups. We report the median SB for all covariates.

c Critical value of Rosenbaum's $\Gamma$. 


\subsection{NPAs' effect on deforestation inside their borders}

At the national level, we cannot reject the null hypothesis of a zero average effect of pre-1993 NPAs on clearing inside their borders (Table 2). All of the matching estimators generate small and statistically insignificant ATT estimates.

The two naïve estimators that do not control for selection bias, both of which generate statistically significant ATTs, paint a very different picture (Table 2). They suggest that at the national level, NPAs reduced deforestation rate by $26-31$ percent. Note that MSB for these estimators ranges from 14 to 22 percent, another indication that on average, NPA plots are very different from nonNPA plots-even those that are quite close by-in terms of the land characteristics that drive deforestation.

Turning to the regional subsamples, matching estimators only clearly indicate that NPAs were effective in stemming deforestation in one of the nine CONANP regions: Region 6, which accounts for 36 percent of all NPA plots in our national sample. In that region, all ATT estimates are statistically significant at the 1 or 5 percent level. The matching estimators suggest that NPAs cut clearing by $56-72$ percent. As in the national sample, these matching ATTs are lower than the naïve ATTs.

The only other region in which our preferred covariate estimators generate significant ATTs is Region 3, which accounts for 27 percent of all NPA plots in our national sample. Here, the covariate matching estimators, which are significant at the 1 and 10 percent levels, suggest NPAs increased deforestation by 131156 percent. We note, however, that neither of the two propensity score matching estimators for Region 3 is statistically significant, which suggests these results are not as robust as those for Region 6 . In any case, we consider possible explanations for our Region 3 results in the Discussion section.

The anomalous effect of the NPAs in Region 3 begs the question of whether these protected areas drive our finding that at the nationallevel, the average NPA does not have a statistically significant effect on deforestation. To address that question, we drop Region 3 from the national sample and re-estimate ATTs (Table 2, last column). For this subsample, the matching analysis suggests that on average, pre1993 NPAs cut deforestation by 43-51 percent. All ATT estimates are statistically significant at the 1 percent level.

\subsection{NPAs' effect on deforestation outside their borders}

At the national-level, we are not able to reject the null hypothesis of a zero average effect of pre-1993 NPAs on clearing within $20 \mathrm{~km}$ of their borders (Table 3). Evidence that these NPAs had spillover effects on deforestation is confined to Region 6 and Region 9. Spillovers in Region 6 were positive; that is, NPAs had the same type of effect on deforestation both inside and outside their borders. They reduced deforestation inside their borders by $56-72$ percent, and reduced it by 23-29 percent outside.

In Region 9, by contrast, spillovers were, loosely speaking, negative. Inside-NPA treatment effects generated by the four matching estimators are all negative, although only one is statistically significant. The implications is that if NPAs had any effect on deforestation inside their borders, it was to reduce it. The matching estimators clearly indicate that NPAs increased deforestation outside their borders, however. All four matching estimators are statistically significant at the 1 or 5 percent level. The magnitude of these effects ranges from 34 to 46 percent.

\subsection{Sensitivity analysis}

We calculate Rosenbaum bounds to check the sensitivity of our results to unobserved heterogeneity (Rosenbaum, 2002; Aakvik, 2001). Rosenbaum bounds indicate how strongly unobserved confounding factors would need to influence selection into the treatment in order to undermine a statistically significant ATT. To be more specific, the Rosenbaum procedure adapted to a binary outcome generates a probability value for Mantel and Haenszel (1959) test statistic for a series of values of $\Gamma$, an index of the strength of the influence that unobserved confounding factors have on the selection process. $\Gamma=1$ implies that unobserved confounding factors have no influence, such that pairs of plots matched on observables do not differ in their odds of being treated; $\Gamma=2$ implies that matched pairs could differ in their odds of treatment by as much as a factor of two because of unobserved confounding factors; and so forth. The probability value on the Mantel and Haenszel statistic is a test of the null hypothesis of a zero ATT given unobserved confounding variables that have an effect given by $\Gamma$. So, for example, a probability value of 0.01 and a $\Gamma$ of 1.2 indicate that ATT would still be significant at the one percent level even if matched pairs differed in their odds of protection by a factor of 1.2 because of unobserved confounding factors. Using our preferred nearest neighbor 1-1 covariate matching estimator as a bellwether, we calculate $\Gamma^{*}$, the critical value of $\Gamma$ at which ATT is no longer significant at the 10 percent level in each case where ATT is significant. An ATT estimate can be considered highly sensitive to unobserved heterogeneity when $\Gamma^{*}$ is close to unity.

Results indicate that our inside-NPA effects are robust to moderate levels of unobserved heterogeneity (Table 2). For Region $3, \Gamma^{*}$ is 2.6 , for Region 6 , it is 3.8 , and for the sample that includes all regions except 3 , it is 2.0 . However, our spillover effects are more sensitive. For both Region 6 and Region $9, \Gamma^{*}$ is 1.6. Hence, this second set of results must be interpreted with caution.

\subsection{Characteristics of effective NPAs}

Our analysis of how NPA characteristics mediate their effects on deforestation inside their boundaries suggests that NPAs that were larger, newer, mixed use and that were allocated more funding, were more effective (Table 4). For each of the four NPA characteristics we consider, an interaction term in a probit regression using matched controls is statistically significant at the one percent-level. The estimated coefficients on the interactions terms suggest that each additional 100,000 ha in size reduces clearing inside an NPA by 2 percent, and that each additional year in age increases clearing by about the same amount. Furthermore, mixed use management reduces clearing by 71 percent, and GEF funding reduces it by 60 percent.

Table 4

Probit regression results ${ }^{\mathrm{a}}$ : dependent variable = deforested 1993-2000; marginal effects expressed as percent changes. ${ }^{b}$

\begin{tabular}{lllll}
\hline Variable & \multicolumn{2}{l}{ Interaction } & & \\
\cline { 2 - 5 } & Area & Vintage & Mixed use & $\begin{array}{l}\text { GEF } \\
\text { funding }\end{array}$ \\
\hline NPA ${ }^{*}$ Interaction & $-1.71 \mathrm{E}-4^{* * *}$ & $1.85^{* * *}$ & $-70.81^{* * *}$ & $-59.61^{* * *}$ \\
No. observations & 6191 & 6191 & 6191 & 6191 \\
Pseudo- $R^{2}(\%)$ & 6.36 & 5.59 & 5.19 & 5.02 \\
Prob. $>\mathrm{chi}^{2}$ & 0.00 & 0.00 & 0.00 & 0.00 \\
\hline
\end{tabular}

$* p<10 \%$.

** $p<5 \%$.

$p<1 \%$

$\mathrm{n} / \mathrm{a}$, not applicable.

a All regressions feature: a national sample comprising plots in all CONANP regions except Region 3; matched control observations identified using Mahalanobis one-to-one procedure with replacement; the six control variable in Table 1 and standard errors clustered at the municipio-level. Observations are weighted based on the number of times they are used as matches.

b Percent change is calculated as $\left(M / R_{\mathrm{C}}\right) \times 100$ where $M$ is the marginal effect of the interaction term and $R_{\mathrm{C}}$ is the average deforestation rate for matched control (counterfactual) plots. 


\section{Discussion}

In this section, we focus on three aspects of our results: NPAs' heterogeneous effects on deforestation inside their borders, possible explanations for NPAs' effects in Region 3, and possible explanations for NPAs' spillover effects on deforestation outside their borders.

\subsection{NPAs' heterogeneous effects on deforestation inside their borders}

We find that depending on their characteristics, NPAs had different effects on deforestation inside their borders. NPAs in Region 6 were more effective at stemming deforestation than those elsewhere. In addition, we found that in a national sample, NPA effectiveness was positively correlated with size, mixed use management, and funding and negatively correlated with age.

Most of those correlations comport with previous research. For example, studies of protected areas in countries other than Mexico have found that effectiveness is positively correlated with protected area size (Joppa et al., 2008; DeFries et al., 2005), mixed-use management (Blackman, 2014; Pfaff et al., 2014b; Nelson and Chomitz, 2011), and funding (Bruner et al., 2001, 2004; Wilkie et al., 2001). Size is hypothesized to boost effectiveness because land near NPA borders buffers against encroachment on interior land. Mixed-use management is hypothesized to improve effectiveness because given appropriate incentives, local communities can sometimes do a better job of stemming forest-cover change than underfunded state authorities. And the link between funding and effectiveness is clear: it facilitates monitoring, enforcement, and planning.

A natural question, however, is whether in our data, these associations between park characteristics and effectiveness reflect causation or spurious correlation. For example, it could be that GEF funding for elite NPAs was a critical determinant of effectiveness in the 1990s and that GEF funding tended to be allocated to large NPAs. If that were true, then the correlation between effectiveness and funding would reflect causation but the correlation between effectiveness and NPA size would be spurious.

Unfortunately, we are not able to differentiate between these two types of associations. The reason is that most of the NPA characteristics we consider are highly correlated with each other. For example, at the plot level, the simple correlation coefficients between funding, on one hand, and NPA size, vintage, and location in Region 6, on the other, all exceed 60 percent, and the correlation between funding and mixed-use management exceeds 40 percent. As a result, it is not possible to disentangle the effects of various park characteristics by, for example, using including multiple interaction effects in a single regression, or testing for correlations using subsamples.

\subsection{Effect in Region 3}

Our covariate matching results suggest that, rather than stemming deforestation, NPAs in Region 3 actually spurred it. This result is by no means unprecedented: studies in other countries also have demonstrated that protected areas can exacerbate deforestation (Petursson et al., 2012; Wittemyer et al., 2008; Liu et al., 2001). A common explanation is that poorly managed, under-resourced protected areas with little or no enforcement of land-use and land-cover change restrictions become open-access regimes that lead to a tragedy of the commons.

Determining whether these, or other factors explain our results for Region 3 is beyond the scope of our paper. However, we offer two types of preliminary evidence. First, interviews with CONANP officials suggest that the above explanation may indeed apply
(Sánchez Ibarra, 2011). Prior to 2000, when a regional CONANP office was first established, enforcement of NPA protections in Region 3 was negligible and illegal logging was rampant. Moreover, the prospect of more stringent enforcement due to the establishment of that CONANP office, and the threat of state expropriation of NPA land, may have prompted local agents to preemptively clear land in NPAs.

Second, our data indicate that observable characteristics of the pre-1993 NPAs in Region 3 differ from those in other regions. Specifically, plots in Region 3 tend to be farther from cities, higher, flatter, drier, on land with communal tenure, and in localities with heavily indigenous population (Table 5). In principle, these characteristics could help explain our results. For example, NPAs that are particularly far from cities may be more difficult for regulatory authorities to monitor and manage.

\subsection{Heterogeneous effects on deforestation outside NPA borders}

Finally, we find that just as different categories of NPAs had heterogeneous effects on deforestation inside their borders, they also had heterogeneous spillover effects on deforestation just outside their borders. NPAs in Region 6 had the same dampening effect on deforestation inside and outside their borders. NPAs in Region 9, by contrast, had weak or insignificant effects on deforestation inside their borders but raised it outside.

Our finding that NPAs had heterogeneous spillover effects also comports with the literature. In principle, all manner of forest conservation policies can have varied spillover effects (Baylis et al., 2013; Alix-Garcia et al., 2012; Pfaff and Robalino, 2012). Several causal mechanisms have been hypothesized. For example, protected areas can reduce deforestation both inside and outside their borders-the phenomenon we observe in Region 6-by changing nearby land managers' attitudes toward conservation, and/or creating incentives for them to preserve forests for the sake of ecotourism. In addition, in some settings, state authorities may intentionally restrict road and other infrastructure investments in areas adjacent to parks (Pfaff and Robalino, 2012).

In principle, protected areas can also have negligible effects on deforestation inside their borders and exacerbate it outside-the phenomenon we observe in Region 9-by spurring tourism, infrastructure development, and population growth outside their borders (Scholte, 2003; Wittemyer et al., 2008). (Note however, that a complementary study finds a negative correlation between the creation of Mexican NPAs between 2000 and 2005 and nearby population growth; see Robalino et al., 2012b). Protected areas also may incentivize preemptive clearing by nearby land managers

Table 5

Probit regression results ${ }^{\mathrm{a}}$ : dependent variable $=$ location in Region 3; marginal effects expressed as percentage point changes.

\begin{tabular}{ll}
\hline Variable & Marginal effect \\
\hline Communal tenure & $10.91^{* * *}$ \\
Indigenous population & $16.57^{* * *}$ \\
Travel time to city & $0.02^{* * *}$ \\
Altitude & $0.01^{* * *}$ \\
Slope & $-0.04^{*}$ \\
Rain & $-0.03^{* * *}$ \\
& \\
No. observations & 5574 \\
Pseudo- $R^{2}(\%)$ & 50.73 \\
prob. $>$ chi $^{2}$ & 0.00 \\
${ }^{*}{ }^{*} p<10 \%$ & \\
${ }^{* * *} p<5 \%$ & \\
& \\
& $p<1 \%$.
\end{tabular}


who fear the expansion of protection (Baylis et al., 2013; Lueck and Michael, 2003; Ferraro et al., 2007).

\section{Conclusion}

We have used high-resolution land-cover change data derived from satellite images along with matching techniques that control for nonrandom siting and spatial spillovers to measure the effectiveness of Mexico's 56 pre-1993 NPAs in stemming deforestation between 1993 and 2000, a period when these 'paper parks' received minimal financial and human resources. Our principal findings are as follows. First, most of our estimates of the magnitude of NPAs' effects on deforestation inside their borders are significantly smaller than those generated by naïve methods that do not control for nonrandom siting, a common finding in evaluations of forest conservation policies that use matching and other quasi-experimental techniques. Second, NPAs had heterogeneous effects on deforestation inside their borders. At the nationallevel, we cannot reject the null hypothesis of a zero average effect of NPAs on forest clearing inside their borders. However, NPAs in certain regions had statistically and economically significant effects. Not all of these effects were in the desired direction though; in one region (Region 3), we find some evidence that NPAs spurred rather than stemmed deforestation. Third, NPAs with certain characteristics-specifically those that were large, new, mixed use, and relatively well funded-were more effective than average in cutting deforestation inside their borders. And finally, NPAs had heterogeneous spillover effects on deforestation outside their borders. In one region (Region 9), NPAs exacerbated deforestation just outside their borders, and in another (Region 6), they helped stem it.

What are the implications of these findings for policy and research? On one hand, they suggest that protected areas can have forest conservation benefits, even when severely under-resourced. Although our findings hint at the characteristics of protected areas associated with effectiveness, we are not able to reliably differentiate between causal and spurious correlations. Further research is needed to address this question. Similar remote sensing studies with a larger sample of protected areas or complementary studies using other types of data could be helpful.

On the other hand, however, our results also support a finding of several other studies: paper parks can spur deforestation, presumably by creating de facto open-access management regimes. Here, too, further research using more and different types of data can help identify the characteristics of paper parks that generate these perverse effects.

\section{Acknowledgments}

Funding for this research was provided by the Tinker Foundation, the National Space and Aeronautics Administration through the SERVIR Applied Science Team, the Swedish International Development Corporation Agency, Sida, through the Environment for Development (EfD) Initiative, and the Swedish Research Council, Formas, through the Human Cooperation to Manage Natural Resources (COMMONS) program. We are grateful to Nisha Krishnan and Yatziri Zepeda for expert research assistance; to Zepeda and the National Ecology and Climate Change Institute for providing data; to Sally Atwater for editing; and to Carlos Enriquez, Adriana Moreira, Carlos Muñoz, Marisol Rivera, Cesar Sánchez, Alberto Sandoval, Alejandro Vasquez, Laura Villalobos and two anonymous reviewers for helpful comments and suggestions.

\section{Appendix A. Mexico's 56 pre-1993 natural protected areas and additional results}

Table A1
Table A1

Pre-1993 natural protected areas: number of sample plots, and percentage cleared, 1993-2000, by CONANP region.

\begin{tabular}{lll}
\hline Region, protected area & $\begin{array}{l}\text { Sample } \\
\text { plots }\end{array}$ & $\begin{array}{l}\text { Percentage } \\
\text { cleared, } \\
1993-2000\end{array}$ \\
\hline
\end{tabular}

Region 1

Constitución de 1857

El Vizcaino

Islas del Golfo de California ${ }^{a}$

Sierra de San Pedro Martir

Total

Region 2

Campo Verde

Islas del Golfo de California

Tutuaca $^{\mathrm{a}}$

Total

Region 3

Campo Verde

Cascada de Bassaseachic

Cumbres de Majalca

La Michilia

Papigochic

Tutuaca $^{a}$

Total

Region 4

Cerro de La Silla

El Potosi

Gogorron

Sierra de Alvarez

Total

Region 5

Canon de Rio Blanco ${ }^{a}$

Cofre de Perote

Cuenca Hidro. del Rio Necaxa

Pantanos de Centla

Pico de Orizaba

Total

Region 6

Calakmul

Dzibilchantun

Sian Kaan

Total

Region 7

Cerro de Garnica

Cuencas de los Rios Valle de

Bravo, Malacatepec,

Tilostoc y Temascaltepec ${ }^{a}$

El Jabali

Insurg. Jose Maria Morelos

La Primavera

Nevado de Colima

Pico de Tancitaro

Sierra de Manantlan

Sierra de Quila

Total

Region 8

Canon de Rio Blanco ${ }^{a}$

Cobio Chichinautzin

Cuencas de Los Rios Valle de

Bravo, Malacatepec,

Tilostoc y Temascaltepec ${ }^{a}$

Cumbres del Ajusco

Desierto de Los Leones

El Chico

El Tepozteco

El Veladero

Grutas de Cacahuamilpa

Insur. Miguel Hidalgo y Costilla

Iztaccihuatl-Popocatepetl

Lagunas de Zempoala

Los Marmoles

Malinche o Matlalcueyatl

Nevado de Toluca

Pico de Orizaba ${ }^{a}$

Total

Region 9

Benito Juarez

Bonampak

$\begin{array}{rr}9 & 11 \\ 1 & 0 \\ 4 & 0 \\ 91 & 7 \\ 105 & 7 \\ & \\ 28 & 7 \\ 12 & 0 \\ 41 & 5 \\ 81 & 5 \\ & \\ 202 & 1 \\ 11 & 9 \\ 12 & 0 \\ 13 & 38 \\ 492 & 47 \\ 785 & 18 \\ 1515 & 25\end{array}$

11

7

7

5

1

7

18
25

50

$4-0$

$\begin{array}{ll}11 & 0 \\ 21 & 5\end{array}$

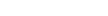

$45-2$

20

0

3
24

$3-0$

47

25

46
52

1

$\begin{array}{rr}64 & 18\end{array}$

$10-20$

2 - 0

20

$46 \quad 4$

12
22

42

45

17

332

7

11
2

40
20

0
0
5
2

2
40
20
0
20
14


2
0
0
4
3


0
0
25

14

2

0
0
5
2

2
40
20
0
20
14


2
0
4
4
3


0
25

0

2

0
0
5
2

2
40
20
0
20
14


2
0
0
4
3


0
0
25

0

0
0
5
2

2
40
20
0
20
14


2
0
0
4
3


0
0
25

13
16

7

0 $\begin{array}{ll}1 & 0 \\ 6 & \end{array}$ 


\section{Table A1 (Continued)}

\begin{tabular}{lrc} 
Region, protected area & $\begin{array}{l}\text { Sample } \\
\text { plots }\end{array}$ & $\begin{array}{l}\text { Percentage } \\
\text { cleared, } \\
1993-2000\end{array}$ \\
\hline Canon del Sumidero & 36 & 17 \\
Cascada de Agua Azul & 5 & 20 \\
Chan-Kin & 5 & 0 \\
El Triunfo & 241 & 3 \\
Lacan-Tun & 8 & 0 \\
Lagunas de Chacahua & 19 & 5 \\
Lagunas de Montebello & 3 & 33 \\
Montes Azules & 639 & 8 \\
Palenque & 1 & 0 \\
Yaxchilan & 3 & 0 \\
Total & 978 & 7
\end{tabular}

${ }^{\mathrm{a} N P A}$ spans two regions.

\section{References}

Aakvik, A., 2001. Bounding a matching estimator: the case of a Norwegian training program. Oxf. Bull. Econ. Stat. 63, 115-143.

Abadie, A., Imbens, G., 2006. Large sample properties of matching estimators for average treatment effects. Econometrica 74 (1), 235-267.

Alix-Garcia, J., Shapiro, E., Sims, K., 2012. Forest conservation and slippage: evidence from Mexico's National Payments for Ecosystem Services Program. Land Econ. 88 (4), 613-638.

Andam, K., Ferraro, P., Pfaff, A., Robalino, J., Sanchez, A., 2008. Measuring the effectiveness of protected-area networks in reducing deforestation. Proc. Natl. Acad. Sci. U. S. A. 105 (42), 16089-16094.

Anta Fonseca, S., 2006. Forest certification in Mexico. In: Cashore, B., Gale, F. Meidinger, E., Newsom, D. (Eds.), Confronting sustainability: forest certification in developing and transitioning countries. Yale School of Forestry and Environmental Studies, New Haven.

Balmford, A., Gaston, K., Blyth, S., James, A., Kapos, V., 2003. Global variation in terrestrial conservation costs, conservation benefits, and unmet conservation needs. Proc. Natl. Acad. Sci. U. S. A. 100 (3), 1046-1050.

Baylis, K., Fullerton, D., Shah, P., 2013. What drives forest leakage? Working Paper. Department of Agricultural and Consumer Economics, University of Illinois at Urbana-Champaign.

Blackman, A., 2013. Evaluating forest conservation policies in developing countries using remote sensing data: an introduction and practical guide. For. Policy Econ. $34,1-16$.

Blackman, A., 2014. Strict versus mixed use protected areas: Guatemala's Maya Biosphere Reserve. Working paper. Resources for the Future, Washington, DC.

Bonham, C., Scayon, E., Tzi, E., 2008. Protecting imperiled "paper parks": potential lessons from the Sierra Chinajá, Guatemala. Biodivers. Conserv. 17, 15811593.

Bonilla-Moheno, B., Redo, D., Aide, T., Clark, M., Grau, H., 2013. Vegetation change and land tenure in Mexico: a country-wide analysis. Land Use Policy 30 (1), 355-364.

Boucher, D., Elias, P., Lininger, K., May-Tobin, C., Roquemore, S., Saxon, E., 2011. The root of the problem. What's driving tropical deforestation today? Union of Concerned Scientists.

Bovarnick, A., Fernandez-Baca, J., Galindo, J., Negret, H., 2010. Financial sustainability of protected areas in Latin America and the Caribbean: investment policy guidance. United Nations Development Programme and The Nature Conservancy.

Bray, D., Antinori, C., Duran, E., Magana, O., Mas, J.F., Ramos, V.H., Tardanico, R., Torres, J.M., Velazquez, A., 2006. Governance in the Maya Forest of Mexico and Guatemala: protected areas and community forests. Paper presented at World Bank Workshop on Sustainable Development: The Role of Better Governance and Improved Institutions, Washington, DC, November 10.

Bruner, A., Gullison, R., Balmford, A., 2004. Financial costs and shortfalls of managing and expanding protected-area systems in developing countries. Bioscience 54 (12), 1119-1126.

Bruner, A., Gullison, R., Rice, R., da Fonseca, G., 2001. Effectiveness of parks in protecting tropical biodiversity. Science 291, 125-128.

Caliendo, M., Kopeinig, S., 2008. Some practical guidance for the implementation of propensity score matching. J. Econ. Surv. 32, 31-72.

Carey, C., Dudley, N., Stolton, S., 2000. Squandering paradise: the importance and vulnerability of the world's protected areas. World Wildlife Federation - World Wide Fund for Nature International, Gland, Switzerland.

Cervigni, R., Brizzi, A., 2001. Biodiversity. In: Guigale, M., Lafourcade, O., Nguyen, V. (Eds.), Mexico: A Comprehensive Development Agenda for the New Era. World Bank, Washington, DC (Chapter 27).

Chomitz, K., 2007. At Loggerheads? Agricultural Expansion, Poverty Reduction and Environment in the Tropical Forests. World Bank, Washington, DC.

Comisión Nacional de Áreas Naturales Protegidas (CONANP), 2003. La deforestatión en 24 regiones proders. Secretaría de Medio Ambiente y Recursos Naturales, Mexico City.
Comisión Nacional de Áreas Naturales Protegidas (CONANP), 2007. Sistema de Información Geográfica. Available at http://www.conanp.gob.mx/sig/

Comisión Nacional para el Conocimiento y Uso de la Biodiversidad (CONABIO), 1998. Total annual precipitation. Available at http://www.conabio.gob.mx/

Comisión Nacional para el Conocimiento y Uso de la Biodiversidad (CONABIO), 1999. Areas Indiginas. Locality level. Mexico. Available at http://www.conabio. gob.mx/

DeFries, R., Hansen, A., Newton, A., Hansen, M., 2005. Increasing isolation of protected areas in tropical forests over the past twenty years. Ecol. Appl. 15, $19-26$.

Durán-Medina, E., Mas, J.F., Velázquez, A., 2005. Land use/cover change in community-based forest management regions and protected areas in Mexico. In: Bray, D.B., Merino-Pérez, L., Barry, D. (Eds.), The Community Forests of Mexico. University of Texas Press, Austin (Chapter 10).

Ferraro, P., Hanauer, M., Miteva, D., Canavire-Bacarreza, G.J., Pattanayak, S., Sims, K., 2013. More strictly protected areas are not necessarily more protective: evidence from Bolivia, Costa Rica, Indonesia, and Thailand. Environ. Res. Lett. 8 (2.)

Ferraro, P., McIntosh, C., Ospina, M., 2007. The effectiveness of listing under the U.S Endangered Species Act: an econometric analysis using matching methods. J. Environ. Econ. Manage. 54 (3), 245-261.

Figueroa, F., Sánchez-Cordero, V., 2008. Effectiveness of natural protected areas to prevent land use and land cover change in Mexico. Biodivers. Conserv. 17, 3223-3240.

Flores, M., 2010. Protected areas. In: Bovarnick, A., Alpízar, F., Schnell, C. (Eds.), Latin America and the Caribbean: a biodiversity superpower. Importance of biodiversity and ecosystems in economic growth and equity in Latin America and the Caribbean: an economic valuation of ecosystems. United Nations Development Programme (Chapter 10).

Food and Agriculture Organization (FAO), 2011. State of the World's Forests 2011. FAO, Rome.

Geldmann, J., Barnes, M., Coad, L., Craigie, I., Hockings, M., Burgess, N., 2013. Effectiveness of terrestrial protected areas in reducing habitat loss and population declines. Biol. Conserv. 161, 230-238.

Gibson, L., Lee, T.M., Koh, L.P., Brook, B., Gardner, T., Barlow, J., Peres, C., Bradshaw, C., Laurance, W., Lovejoy, T., Sodhi, N., 2011. Primary forests are irreplaceable for sustaining tropical biodiversity. Nature 478, 378-381.

Harris, N., Saatchi, S., Petrova, S., Salas, W., Hansen, M., Potapov, P., Lotsch, A., 2012. Baseline map of carbon emissions from deforestation in tropical regions. Science 336, 1573-1576.

Ho, D., Imai, K., King, G., Stuart, E., 2007. Matching as nonparametric preprocessing for reducing model dependence in parametric causal inference. Polit. Anal. 15, 199-236.

Imbens, G., Wooldridge, J., 2009. Recent developments in the econometrics of program evaluation. J. Econ. Lit. 47 (11), 5-86.

Instituto Nacional de Ecología y Cambio Climáctico (INECC), undated. Travel time to nearest populations centers for $2 \mathrm{~km}$ grid.

Instituto Nacional de Estadistica y Geografia (INEGI), undated. Digital elevation map. Available at http://www.inegi.org.mx/inegi/default.aspx?s=geo.

Joppa, L., Pfaff, A., 2009. High and far: biases in the location of protected areas. PLoS ONE 4, e8273, http://dx.doi.org/10.1371/journal.pone.0008273.

Joppa, L., Pfaff, A., 2010. Reassessing the forest impacts of protection. Ann. N.Y. Acad. Sci. $1185,135-149$.

Joppa, L., Loarie, S., Pimm, S., 2008. On the protection of "protected areas". Proc. Natl Acad. Sci. U. S. A. 105 (18), 6673-6678.

Kaimowitz, D., Angelsen, A., 1998. Economic Models of Tropical Deforestation: A Review. Center for International Forestry Research, Bogor, Indonesia.

Liu, J., Linderman, M., Ouyang, Z., An, L., Yang, J., Zhang, H., 2001. Ecological degradation in protected areas: the case of Wolong Nature Reserve for giant pandas. Science 292, 98-101.

Lueck, D., Michael, J., 2003. Preemptive habitat destruction under the Endangered Species Act. J. Law Econ. 46, 27-60.

Mantel, N., Haenszel, W., 1959. Statistical aspects of the analysis of data from retrospective studies. J. Natl. Cancer Inst. 22, 719-748.

Madrid, L., Núñez, J.M., Quiroz, G., Rodríguez, Y., 2010. La propiedad social forestal en México. Invest. Ambient. 1 (2), 179-196.

Mas, J.F., 2005. Assessing protected areas effectiveness using surrounding (buffer) areas environmentally similar to the target area. Environ. Monit. Assess. 105, $69-80$

Nagendra, H., 2008. Do parks work? Impact of protected areas on land cover clearing. Ambio 37, 330-337.

Naughton-Treves, L., Holland, M.B., Brandon, K., 2005. The role of protected areas in conserving biodiversity and sustaining local livelihoods. Annu. Rev. Environ. Resour. 30, 219-252

Nelson, A., Chomitz, K., 2011. Effectiveness of strict vs. multiple use protected areas in reducing tropical forest fires: a global analysis using matching methods. PLoS ONE 6, e22722.

Pérez Gil Salcido, R., 1995. Natural protected areas in Mexico. George Wright Forum 12 (4), 3038.

Petursson, J.G., Vedeld, P., Sassen, M., 2012. An institutional analysis of deforestation processes in protected areas: the case of transboundary Mt. Elgon, Uganda and Kenya. For. Policy Econ. 26, 22-33.

Pfaff, A., Santiago-Avila, F., Carnovale, M., Joppa, L., 2014a. Protected areas' impacts upon land cover within Mexico: the need to add politics and dynamics to static land-use economics. Working Paper. Sanford School of Public Policy, Duke University, Durham, NC. 
Pfaff, A., Robalino, J., Lima, E., Sandoval, C., Herrera, L.D., 2014b. Governance, location and avoided deforestation from protected areas: greater restrictions can have lower impact, due to differences in location. World Dev. 55, 7-20.

Pfaff, A., Robalino, J., 2012. Protecting forests, biodiversity, and the climate: predicting policy impact to improve policy choice. Oxf. Rev. Econ. Policy 28 (1), 164-179.

Registro Agrario Nacional (RAN), undated. Land tenure data (Provided by Nacional de Ecologia y Cambiao Climáctico for Zepeda-Medina 2005).

Rivera, M., Muñoz, C., 2006. The economics of natural protected areas in Mexico. Paper presented at OECD workshop, Distributive Issues Related to Biodiversity, Oaxaca, Mexico, April 26-27.

Robalino, J., Pfaff, A., Villalobos, L., 2012a. Evaluating spillover effects of land conservation policies in Costa Rica. Working paper. Centro Agronómico Tropical de Investigación y Enseñanza, Turrialba, Costa Rica.

Robalino, J., Villalobos, L., Blackman, A., Pfaff, A., 2012b. Impacts of protected areas on population growth, inequality, and marginalization in Mexico. Working paper. Centro Agronómico Tropical de Investigación y Enseñanza, Turrialba, Costa Rica.

Rosenbaum, P., 2002. Observational Studies, 2nd ed. Springer, New York.

Rosenbaum, P., Rubin, D., 1983. The central role of the propensity score in observational studies for causal effects. Biometrika 70, 41-55.

Sánchez Ibarra, C., 2011. Director de Represnetitividad y Creacion de Nuevas Áreas Protegidas, Comision Nacional de Áreas Naturales Protegidas. Personal interview with authors, Mexico City, Mexico, March 9.
Scholte, P., 2003. Immigration: a potential time-bomb under the integration of conservation and development. Ambio 32, 58-64.

Sims, K., Alix-Garcia, J., 2014. It's complicated: direct vs. incentive-based land conservation in Mexico. Working paper. Department of Economics, Amherst College, Amherst, MA.

Stuart, E., 2010. Matching methods for causal inference: a review and a look forward. Stat. Sci. 25 (1), 1-21.

Velázquez, A., Mas, J.F., Palacio, J.L., 2002. Análisis del cambio de uso del suelo. Instituto Nacional de Ecología-Instituto de Geografía, Universidad Nacional Autónoma de México.

Wilkie, D., Carpenter, J., Zhang, Q., 2001. The under-financing of protected areas in the Congo Basin: so many parks and so little willingness-to-pay. Biodivers. Conserv. 10 (5), 691-709.

Wittemyer, G., Elsen, P., Bean, W., Coleman, A., Burton, O., Brashares, J., 2008. Accelerated human population growth at protected area edges. Science 321 (5885), 123-126.

World Bank, 2002. Project appraisal document on a proposed grant for the Global Environment Facility Trust Fund in the amount of SDR 12.8 million to Nacional Financiera, S.N.C. and Fondo Mexicano para la conservacion de la Naturaleza, AS for a consolidation of the protected area system project. Report No. 23359 ME. Annex 14

World Database on Protected Areas (WDPA). 2014. Available at www. protectedplanet.net (accessed 14.01.14). 